\title{
Boscalid Resistance in Blumeriella jaapii: Distribution, Effect on Field Efficacy, and Molecular Characterization
}

\author{
Cory A. Outwater, ${ }^{1}$ Tyre J. Proffer, ${ }^{1,2}$ Nikki L. Rothwell, ${ }^{3}$ Jingyu Peng, ${ }^{1}$ and George W. Sundin ${ }^{1, \dagger}$ \\ ${ }^{1}$ Department of Plant, Soil, and Microbial Sciences, Michigan State University, East Lansing, MI 48824; ${ }^{2}$ Department of Biolog- \\ ical Sciences, Kent State University, Salem, OH 44460; and ${ }^{3}$ Northwest Michigan Horticultural Research Center, Traverse City, \\ MI 49684
}

\begin{abstract}
Cherry leaf spot (CLS), caused by the fungus Blumeriella jaapii, is a major disease of tart cherry (Prunus cerasus L.) trees, leading to early defoliation that results in uneven ripening and poor fruit quality in the current season, reduced fruit set in the following season, and increased potential for winter injury and tree death. Pristine (BASF Corporation, Research Triangle Park, NC), a commonly used fungicide for CLS management in Michigan, is a premix of boscalid, a succinate dehydrogenase inhibitor, and pyraclostrobin, a quinone outside inhibitor. Reduced efficacy of Pristine for CLS control was observed in field trials and commercial orchards and highlights the importance of fungicide resistance monitoring. A total of 1,189 isolates from 31 commercial orchards in Michigan, 111 isolates from nontreated trees (four locations in Michigan and two locations in Ohio), and 133 isolates from a research orchard were collected during 2010, 2011, and 2012 and assayed on boscalid-amended media at concentrations ranging from 0 to $25 \mu \mathrm{g} \mathrm{ml}^{-1}$. Because of the very slow

growth rate of $B$. jaapii in culture, we determined the minimum inhibitory concentration (MIC) of boscalid as opposed to the effective concentration that inhibits mycelial growth to $50 \%$ of the control. Isolates from nontreated trees had MIC values ranging from 0.1 to $0.5 \mu \mathrm{g} \mathrm{ml}^{-1}$; the MIC of isolates from commercial orchards ranged from 0.1 to $>25 \mu \mathrm{g} \mathrm{ml}^{-1}$, and isolates from the research orchard ranged from 2.5 to $>25 \mu \mathrm{g}$ $\mathrm{ml}^{-1}$. Isolates with MIC values $\geq 25 \mu \mathrm{g} \mathrm{ml}^{-1}$ were considered boscalid resistant and comprised $0 \%$ of the nontreated isolates, $30.4 \%$ of the commercial isolates, and $42.1 \%$ of the research orchard isolates. Sequencing of the sdhB gene of resistant isolates led to the detection of the amino acid mutation H260R, which is known to confer boscalid resistance in other phytopathogenic fungi. Our results indicate that the occurrence of the H260R mutation in Michigan populations of B. jaapii is correlated with the reduction in sensitivity to boscalid observed in commercial orchards.
\end{abstract}

Cherry leaf spot (CLS), caused by the fungus Blumeriella jaapii (Rehm) Arx, is the most important disease of tart cherry (Prunus cerasus L.) in Michigan. If orchards are left untreated, CLS infection can lead to early defoliation, which can result in undersized and unevenly ripened fruit. Trees that undergo severe defoliation caused by CLS will have reduced flower bud formation and poor fruit set the following season (Howell and Stackhouse 1973). In addition, trees that defoliate prematurely are less cold hardy and become more susceptible to winter injury, which can result in tree death under normal overwintering conditions (Keitt et al. 1937). The severity and timing of defoliation coupled with cold winter temperatures can kill entire orchard blocks.

CLS affects all commercially grown cultivars of both sweet (Prunus avium L.) and tart cherries, but it is most severe on tart cherries. The predominant tart cherry cultivar grown in Michigan is cultivar Montmorency. This cultivar requires yearly chemical control programs of six to eight fungicide applications that target CLS. Although multisite fungicides, including captan and chlorothalonil, are registered for CLS control, growers also utilize site-specific

\section{${ }^{\dagger}$ Corresponding author: G. W. Sundin; sundin@msu.edu}

Funding: This work was supported by the Michigan Cherry Committee; the Michigan State Horticultural Society; Michigan State University Project GREEEN (Generating Research and Extension to meet Economic and Environmental Needs), a Michigan plant agriculture initiative at Michigan State University; and Michigan State University AgBioResearch.

*The $\boldsymbol{e}$-Xtra logo stands for "electronic extra" and indicates that one supplementary table is published online.

The author(s) declare no conflict of interest.

Accepted for publication 31 December 2018.

(C) 2019 The American Phytopathological Society fungicides, such as dodine, strobilurins (quinone outside inhibitors [QoIs]; registered for CLS control in 1999), and succinate dehydrogenase inhibitors (SDHIs), because of their effectiveness against CLS as well as other diseases, including powdery mildew and American brown rot (Proffer et al. 2013). In addition, commercially available premixes of site-specific fungicides are marketed for tart cherry disease management, including Pristine (BASF Corporation, Research Triangle Park, NC), a premix of the SDHI boscalid and the QoI pyraclostrobin, which was registered for CLS control in 2004. Site-specific fungicides used for CLS control have a high risk of developing resistance within B. jaapii populations.

The SDH complex, also referred to as complex II or succinate: ubiquinone oxioreductase is a functional component of the aerobic respiratory chain of fungal mitochondria (Cecchini 2003). Complex II consists of four protein subunits (SdhA, SdhB, SdhC, and SdhD) that are arranged into two main domains: the membrane-peripheral domain (SdhA and SdhB subunits) and the membrane-anchor domain (SdhC and SdhD subunits) (Avenot and Michailides 2010). The SdhA and SdhB subunits form the soluble part of the complex and catalyze the oxidation of succinate to fumarate. $\mathrm{SdhB}$ is an iron-sulfur protein that contains three iron-sulfur clusters: [2Fe-2S], [4Fe-4S], and [3Fe-4S] (Ackrell 2000). These iron-sulfur clusters are important in the transfer of electrons between flavin adenine dinucleotide and the membrane quinone (Ackrell 2000).

Resistance to the SDHI class of fungicides has been well documented in numerous agriculturally important pathogens. The first reported case of SDHI resistance was to carboxin in Ustilago maydis (Georgopoulos et al. 1975), and the intensive usage of boscalidtargeting pathogens in diverse agricultural systems has resulted in the evolution of resistance in populations of several pathogens, including Alternaria alternata (Avenot et al. 2008, 2009), Alternaria solani (Wharton et al. 2012), Botrytis cinerea from several pathosystems and geographic regions (Fernández-Ortuño et al. 2017; Leroux et al. 2010; Veloukas et al. 2011; Yin et al. 2011; Zhang et al. 2007), Corynespora cassiicola (Miyamoto et al. 2010), Didymella bryoniae (Keinath 2012), Monilinia fructicola (Chen et al. 2013), 
Podosphaera xanthii (Ishii et al. 2011), and Sclerotinia homoeocarpa (Popko et al. 2018). The molecular basis of boscalid resistance has also been examined in a number of plant-pathogenic fungi. One of the most common mutations identified is a base pair substitution in the succinate dehydrogenase subunit $\mathrm{b}(s d h B)$ gene, resulting in the exchange of a highly conserved histidine in the SdhB protein to either arginine or tyrosine (Avenot and Michailides 2010; Sierotzki and Scalliet 2013). This mutation in $s d h B$ maps to amino acid position 267 in Mycosphaerella graminicola, position 272 in B. cinerea, position 277 in A. alternata and D. bryoniae, and position 278 in A. solani (Mallik et al. 2014; Sierotzki and Scalliet 2013). The conserved histidine residue at this position occurs at the bottom of a polar cavity located within the ubiquinone-binding pocket that is formed at the interface of the SdhB, SdhC, and SdhD protein subunits (Sierotzki and Scalliet 2013). It has been hypothesized that an amino acid alteration at this conserved histidine residue may cause a conformational change in the binding pocket that retains normal functioning for fungal respiration but no longer facilitates the binding of the boscalid molecule (Avenot and Michailides 2010).

Pristine was registered commercially in 2004 for CLS management in tart cherry in Michigan, and it was heavily used, because this material provided excellent control of CLS at a time when practical resistance to the demethylation-inhibiting (DMI) fungicides in Michigan orchards had emerged in B. jaapii (Proffer et al. 2006). The widespread resistance of $B$. jaapii to DMI fungicides has essentially eliminated this class of fungicides for the control of CLS in Michigan orchards (Ma et al. 2006; Proffer et al. 2006). In addition to boscalid, Pristine contains a second mode of action in the premix, the QoI pyraclostrobin, but research trials have shown that pyraclostrobin has relatively lower intrinsic activity against CLS, whereas boscalid exhibits excellent efficacy (Sundin et al. 2006).

Based on these initial results, we hypothesized that applications of Pristine for CLS control put extensive selection pressure on the boscalid component, which would likely hasten the development of resistance, resulting in reduced efficacy of this fungicide mixture. We have observed a reduction in the efficacy of Pristine for CLS control in commercial tart cherry orchards in Michigan (N. L. Rothwell and G. W. Sundin, unpublished observations). The objectives of this study were to (i) determine the occurrence and distribution of boscalid resistance in Michigan populations of $B$. jaapii, (ii) determine the effect of boscalid resistance on management of CLS with Pristine, and (iii) identify mutation(s) in the $s d h B$ gene that could result in an amino acid alteration(s) within the $\mathrm{SdhB}$ subunit of $B$. jaapii that is correlated with boscalid resistance.

\section{Materials and Methods}

Fungicide efficacy trials. Fungicide efficacy trial experiments on tart cherry were conducted at the Northwest Michigan Horticultural
Research Center (NWMHRC) near Traverse City, Michigan in 2011, 2012 , and 2013. Six fungicide applications were made at $\sim 10$-day intervals beginning at the petal fall stage of tree development. Fungicides (and rates of active ingredients) were tested either in full season (six application) programs or in a program in which the first two applications were chlorothalonil followed by four applications of the fungicide of interest (Table 1). Spray dates according to phenological timing used in each experiment are listed in Supplementary Table S1. Experiments were conducted in a block of tart cherry Montmorency trees established in 1995. Fungicide sprays were applied to individual trees to runoff using a portable hand-gun sprayer at a rate of 330 to $386 \mathrm{~kg} \mathrm{~cm}^{-2}$ and 458.9 liter water ha ${ }^{-1}$.

Experiments were set up in a randomized complete block design with single-tree plots and four replications per fungicide treatment. CLS disease ratings were conducted at harvest and $\sim 4$ to 6 weeks after harvest. To rate for disease, we examined the disease incidence and defoliation caused by CLS on 20 randomly selected shoot terminals from each tree. For each terminal, the total number of nodes and the total number of leaves with CLS symptoms were counted; with this method, we are able to determine the total number of defoliated leaves.

Statistical analysis of field data. Fungicide treatments were evaluated for their effectiveness of controlling CLS incidence and defoliation on Montmorency tart cherry using a one-way analysis of variance for each of the rating timings. Data were analyzed using the analysis of variance and least significant difference mean comparison function (Fisher's protected least significant difference test) of ARM (version 9.2; Gylling Data Management Inc., Brookings, $\mathrm{SD})$. Percentage data were subjected to an arcsine square root transformation before analyses.

B. jaapii isolate collection. A total of 31 commercial orchards were selected and sampled in 2010 and 2011 based on grower observations of reduced CLS control where Pristine had been used in fungicide programs. In addition, we obtained CLS samples from nontreated trees from two sites in Ohio (Columbiana and Cuyahoga Counties) and four sites in Michigan (three in Ingham County and one in Livingston County) that were never exposed to fungicides and from the research orchard at the NWMHRC where Pristine had been used in experimental trials for multiple years. The research orchard isolates were collected from nonsprayed control trees in 2011 and 2012 in the experimental block that we used for the fungicide efficacy tests for this study (Table 1). Approximately 30 to 40 individual leaves with CLS symptoms (one leaf per tree) were randomly sampled from orchards, placed in plastic bags, and brought to the laboratory on ice. Cirrhi from sporulating acervuli were streaked onto coffee water agar (20\% brewed coffee and $2 \%$ agar) and incubated at $24^{\circ} \mathrm{C}$ for $24 \mathrm{~h}$. Single germinated conidia were selected, transferred to, and maintained on $2 \%$ malt extract, $0.1 \%$ yeast extract, and $2 \%$ agar (MMEA) agar. When monoconidial isolates

Table 1. Fungicide spray programs utilized in cherry leaf spot and powdery mildew disease control experiments conducted at the Northwest Michigan Horticultural Research Center from 2011 to 2013

\begin{tabular}{|c|c|c|c|c|c|c|c|}
\hline \multirow{2}{*}{$\begin{array}{l}\text { Treatment } \\
\text { description }^{x}\end{array}$} & \multirow[b]{2}{*}{ Years } & \multicolumn{6}{|c|}{ Phenological stages and fungicides $\left(\mathrm{g} \mathrm{ha}^{-1}\right)$ applied $^{y}$} \\
\hline & & Bloom or petal fall & Shuck split & First cover & Second cover & Third cover & Fourth cover \\
\hline Control & 2011 to 2013 & $-^{\mathrm{z}}$ & - & - & - & - & - \\
\hline B + Py FS & 2011 & B $212+$ Py 108 & B $212+$ Py 108 & B $212+$ Py 108 & B $212+$ Py 108 & B $212+$ Py 108 & B $212+$ Py 108 \\
\hline $\mathrm{Fx}+\mathrm{Py} F S$ & 2011 & Fx $100+$ Py 100 & Fx $100+$ Py 100 & Fx $100+$ Py 100 & Fx $100+$ Py 100 & Fx $100+$ Py 100 & Fx $100+$ Py 100 \\
\hline $\operatorname{Tr} \mathrm{FS}$ & 2011 & $\operatorname{Tr} 138$ & $\operatorname{Tr} 138$ & $\operatorname{Tr} 138$ & $\operatorname{Tr} 138$ & $\operatorname{Tr} 138$ & $\operatorname{Tr} 138$ \\
\hline $\mathrm{B}+$ Py program $(\mathrm{P} 1)$ & 2012 & Ch 2780 & Ch 2780 & B $221+$ Py 112 & B $221+$ Py 112 & B $221+$ Py 112 & B $221+$ Py 112 \\
\hline Fx + Py program $(\mathrm{P} 1)$ & 2012 & Ch 2780 & Ch 2780 & Fx $100+$ Py 100 & Fx $100+$ Py 100 & Fx $100+$ Py 100 & Fx $100+$ Py 100 \\
\hline B + Py program (P2) & 2013 & Ch 3363 & Ch 3363 & B $221+$ Py 112 & B $221+$ Py 112 & B 221 + Py 112 & B 221 + Py 112 \\
\hline $\mathrm{Fx}+$ Py program $(\mathrm{P} 2)$ & 2013 & Ch 3363 & Ch 3363 & Fx $100+$ Py 100 & Fx $100+$ Py 100 & Fx $100+$ Py 100 & Fx $100+$ Py 100 \\
\hline Tr program $(\mathrm{P} 1)$ & 2012 & Ch 2780 & Ch 2780 & $\operatorname{Tr} 138$ & $\operatorname{Tr} 138$ & $\operatorname{Tr} 138$ & $\operatorname{Tr} 138$ \\
\hline
\end{tabular}

$\mathrm{x}$ Treatment description refers to compound and seasonal use. FS indicates full season. P1 refers to program treatments run in 2012 utilizing chlorothalonil at 2,780 $\mathrm{g} \mathrm{ha}^{-1}$, and P2 refers to program treatments run in 2013 utilizing chlorothalonil at 3,363 $\mathrm{g} \mathrm{ha}^{-1}$.

y Fungicide common names, brand names, formulations used, and manufacturer are as follows: B, boscalid (Pristine 38WG [boscalid + pyraclostrobin (Py)]; BASF Corp., Research Triangle Park, NC); Ch, chlorothalonil (Bravo Ultrex 82.5\%WDG or Bravo Weather Stik 720SC; Syngenta Crop Protection, Inc., Greensboro, NC); Fx, fluxapyroxad (Merivon 4.17SC [fluxapyroxad + pyraclostrobin]; BASF Corp., Research Triangle Park, NC); and Tr, trifloxystrobin (Gem 500SC; Bayer Crop Science LP, Research Triangle Park, NC). Numbers refer to the amount of active ingredient applied (grams hectare ${ }^{-1}$ ).

${ }^{\mathrm{z}}$ No fungicide was applied corresponding to that phenological stage. 
formed a noticeable colony, small agar plugs were taken and transferred to MMEA agar slants for long-term storage at $5^{\circ} \mathrm{C}$.

A combined total of 1,189 isolates from commercial orchards, 111 isolates from nontreated trees, and 133 isolates from an experimental orchard located at the NWMHRC were collected. A total of 323 isolates were collected in 2010, and 866 were collected in 2011. Of the 111 nontreated isolates, 44 were collected in 2010, and 67 were collected in 2011. Of the 133 isolates from the NWMHRC, 95 were collected in 2011, and 38 were collected in 2012. The group of B. jaapii isolates from commercial orchards collected in 2010 consisted of isolates from 20 orchards with a history of site-specific fungicide use for the control of CLS and 1 orchard that was certified as organic, which was not likely to be exposed to site-specific fungicides. Of the orchards sampled in 2010, 20 were located in the major tart cherryproducing areas in northwest Michigan (Leelanau, Grand Traverse, Antrim, and Benzie Counties), and 1 was located in the west central (Oceana County) tart cherry production area. The group of isolates in 2011 were sampled from 21 orchards with a history of site-specific fungicide use. Of these 21 orchards, 16 were located in the major tart cherry-producing areas in northwest Michigan, and 3 were from the major tart cherry production areas in southwest Michigan. The nontreated isolates were obtained from three locations on the Michigan State University Campus, one site in Livingston County in Michigan, and two sites in Ohio (one each in Columbiana and Cuyahoga Counties). These isolates were obtained from tart cherry, sweet cherry, and black cherry (Prunus serotina Ehrh.) trees that, to our knowledge, had never been treated with fungicides.

In vitro sensitivity of $\boldsymbol{B}$. jaapii to boscalid. The in vitro sensitivity of $B$. jaapii to boscalid was assessed using a mycelial growth assay. In initial pilot studies examining isolates from the nontreated set, we determined that the sensitivity to boscalid was equivalent for both mycelia and germinating spores (data not shown). This observation combined with the slow growth of $B$. jaapii and length of time for sporulation to occur in culture led us to favor a mycelial assay. In addition, other studies have shown that mycelial growth may be a more sensitive proxy of boscalid sensitivity than spore germination (Avenot and Michailides 2007; Stammler and Speakman 2006).

The fungicide used in this study was the commercial formulation of Endura (BASF Corporation), which contains $70 \%$ a.i. boscalid. To prepare stock solutions of boscalid, Endura was dissolved in $100 \%$ acetone and adjusted to concentrations of 100,10 , and $5 \mu \mathrm{g} \mathrm{ml}^{-1}$. Sterilized MMEA cooled to $40^{\circ} \mathrm{C}$ was amended with these stock solutions of boscalid to obtain concentrations of $0.1,0.5,1,2.5,5,10$, and $25 \mu \mathrm{g} \mathrm{ml}^{-1}$. Control media consisted of MMEA amended with the highest concentration of acetone that was added to the fungicide-amended media. Mycelial plugs ( 1-mm diameter) were taken from actively growing cultures using a Pasteur pipette and transferred to the fungicide-amended plates. Two replicates of each isolate were used in this study. Isolates were incubated at 23 to $25^{\circ} \mathrm{C}$ for 14 days, at which point the growth of each isolate was evaluated and an minimum inhibitory concentration (MIC) was determined. The MIC of an isolate is defined as the minimum concentration of a.i. required to fully inhibit growth of an isolate. In previous in vitro studies conducted with $B$. jaapii, MICs were used effectively to distinguish different fungicide sensitivity groups within populations (Ma et al. 2006; Proffer et al. 2006). Because $B$. jaapii grows at an extremely slow rate in culture, MICs are more appropriate and accurate than using an effective concentration 50\% for determining the effect of a fungicide on mycelial growth.

Amplification and identification of $s d h B$ of $B$. jaapii. Five isolates from a nontreated Montmorency tart cherry planting and two isolates from a commercial tart cherry orchard in Michigan were chosen for the initial amplification of $s d h B$ of $B$. jaapii. Mycelium from each isolate was spread onto MMEA media and incubated at 23 to $25^{\circ} \mathrm{C}$ until a suitable mass of mycelium had developed to facilitate DNA extraction; $\sim 100 \mathrm{mg}$ of mycelium from each isolate was scraped from the surface of the plate and ground using liquid nitrogen and a bead beater homogenizer (FastPrep-24; MP Biomedicals, Solon, $\mathrm{OH})$. DNA was extracted using the DNeasy Plant Mini Kit (Qiagen, Valencia, CA) following the manufacturer's protocol.
At the time of this study, a published sequence for the $s d h B$ gene of $B$. jaapii was not available. Thus, we utilized $s d h B$ sequences from A. alternata (GenBank accession number EU178853), B. cinerea (GenBank accession number AY726618), C. cassiicola (GenBank accession number AB548738), and M. graminicola (GenBank accession number JF916688), which were aligned and used to design a set of degenerate primers to amplify the $s d h B$ gene of $B$. jaapii. A region of the $s d h B$ gene that was highly conserved between the four species was used to design three forward degenerate primers and one reverse primer. The three forward primers were SDHB-FL (5'-GACYTTCC AYATCTACCGCTG-3'), SDHB-FS (5'-ATYTACCCWCTNCCY CACA-3'), and SDHB-FEL (5'-TGYGCHATGAACATYRAYGG), and the reverse primer was SDHB-R (5'-CCKYGAGCAGTTRAG AATVGTG-3'). Degenerate bases used in the primers are defined as $\mathrm{Y}=(\mathrm{C} / \mathrm{T}), \mathrm{W}=(\mathrm{A} / \mathrm{T}), \mathrm{R}=(\mathrm{A} / \mathrm{G}), \mathrm{K}=(\mathrm{G} / \mathrm{T}), \mathrm{V}=(\mathrm{A} / \mathrm{C} / \mathrm{G}), \mathrm{H}=$ $(\mathrm{A} / \mathrm{C} / \mathrm{T})$, and $\mathrm{N}=(\mathrm{A} / \mathrm{C} / \mathrm{G} / \mathrm{T})$.

Polymerase chain reaction (PCR) amplifications were conducted in a $50-\mu \mathrm{l}$ volume containing $5 \mu \mathrm{l} \mathrm{PCR}$ buffer, $1.5 \mu \mathrm{l} \mathrm{MgCl}_{2}$, $0.4 \mu \mathrm{l}$ dNTPs (New England Biolabs, Inc., Ipswich, MA), $2 \mu \mathrm{l}$ of each primer, $0.4 \mu \mathrm{l}$ of Taq polymerase (New England Biolabs), and $5 \mu \mathrm{l}$ genomic DNA. PCR amplifications were performed with the following conditions: an initial preheating at $94^{\circ} \mathrm{C}$ for $3 \mathrm{~min}$; 40 cycles of denaturation at $94^{\circ} \mathrm{C}$ for $30 \mathrm{~s}$, annealing at $57^{\circ} \mathrm{C}$ for $30 \mathrm{~s}$, and extension at $68^{\circ} \mathrm{C}$ for $1.5 \mathrm{~min}$; and a final extension at $72^{\circ} \mathrm{C}$ for $5 \mathrm{~min}$. Amplified PCR products were separated on $1.5 \%$ agarose gels in $0.5 \times$ Tris-acetate EDTA buffer, purified using a QIAquick PCR Purification Kit (Qiagen), and directly sequenced with each corresponding primer pair at the Genomics Technology Support Facility, Michigan State University. Sequences were analyzed, and a BLASTx search was performed to confirm the amplification of the $s d h B$ gene. The sequence obtained was used to design specific primers to further amplify the $s d h B$ gene, and a successive primerwalking strategy was used to complete the $s d h B$ sequence.

Nucleotide sequence accession numbers. The complete $s d h B$ sequence from B. jaapii isolates 10BOW14 (resistant to boscalid) and 11LIBJMR1 (sensitive to boscalid) were deposited in GenBank under the accession numbers MH879311 and MH824150, respectively.

\section{Results}

Efficacy of Pristine for control of CLS in fungicide field trials at the NWMHRC from 2011 to 2013. CLS disease efficacy trials involving Pristine (boscalid + pyraclostrobin) and a newer SDHI premix fungicide Merivon (fluxapyroxad + pyraclostrobin) were conducted from 2011 to 2013 in a tart cherry orchard block at the NWMHRC. The dates and intensity of CLS infection periods (Eisensmith and Jones 1981) occurring during the field study periods are reported. A total of 10 to 13 infection periods were observed yearly between 2011 and 2013. Moderate to heavy early-season CLS infection periods occurred during each year, and early-season infection periods were most prevalent during the 2011 and 2012 seasons.

In 2011, the efficacy of a full-season treatment (six applications) of Pristine measured as percentage infection and percentage defoliation at two evaluation times was significantly reduced compared with a full-season treatment of the fungicide Merivon. Disease levels in the untreated control treatment were indicative of high disease pressure in the plot during the experiment (Table 1). In 2012, a significant increase in defoliation was observed at both the harvest (7.4-fold increase) and postharvest ( 7.8 -fold increase) evaluations of a Pristine program treatment compared with a Merivon program treatment (Table 2). In this experiment, a trifloxystrobin program treatment included for comparison resulted in disease levels intermediate between the Pristine and Merivon treatments. Similar results were observed in 2013, with reduced efficacy of the Pristine program treatment compared with the Merivon program treatment under high disease pressure (Table 2). Disease levels in the untreated control treatment were indicative of high disease pressure in the plot during these experiments (Table 2).

Sensitivity of $\boldsymbol{B}$. jaapii isolates to boscalid. A total of $111 \mathrm{~B}$. jaapii isolates with no known prior fungicide exposure and 1,188 isolates from commercial orchards sampled in 2010 and 2011 were 
assayed for their sensitivity to boscalid. The sensitivity of isolates to boscalid, determined as an MIC, ranged from 0.1 to $>25 \mu \mathrm{g} \mathrm{ml}^{-1}$. Of the 111 isolates from sites with no known prior fungicide exposure, 108 isolates were inhibited by a concentration of $0.1 \mu \mathrm{g} \mathrm{ml}^{-1}$, and three isolates were inhibited by a concentration of $0.5 \mu \mathrm{g} \mathrm{ml} l^{-1}$ (Fig. 1). Of the 1,188 isolates from commercial orchards with known Pristine applications, only one isolate was inhibited by a concentration of $0.1 \mu \mathrm{g} \mathrm{ml}^{-1}$, and only $10(0.87 \%)$ isolates were inhibited by a concentration of $0.5 \mu \mathrm{g} \mathrm{ml}^{-1}$. The majority of isolates $(68.7 \%)$ were inhibited at concentrations between 1 and $25 \mu \mathrm{g} \mathrm{ml}^{-1}$, and $30.4 \%$ of isolates were not inhibited by $25 \mu \mathrm{g} \mathrm{ml}^{-1}$ of boscalid (Fig. 1).

Determination of practical resistance for commercial orchard populations of $\boldsymbol{B}$. jaapii. Populations of $B$. jaapii from the NWMHRC research plot where Pristine had previously been applied were sampled and subjected to the boscalid sensitivity assay. Isolates from 2011 populations of $B$. jaapii had MIC values that ranged from 2.5 to $>25 \mu \mathrm{g} \mathrm{ml}^{-1}$. Approximately $45 \%$ of isolates in this population had MICs $>25 \mu \mathrm{g} \mathrm{ml}^{-1}$, whereas $0 \%$ of isolates had MICs in the 0.1 to $1-\mu \mathrm{g} \mathrm{ml}^{-1}$ range (Fig. 2). Isolates from $2012 \mathrm{~B}$. jaapii populations had MIC values that ranged from 2.5 to $>25 \mu \mathrm{g} \mathrm{ml}^{-1}$. Approximately $34 \%$ of isolates in this population had MICs $>25 \mu \mathrm{g} \mathrm{ml}^{-1}$, whereas $0 \%$ of isolates had MICs in the $0.1-$ to $1-\mu \mathrm{g} \mathrm{ml}^{-1}$ range (Fig. 2).

From 2010 and 2011, populations of B. jaapii from each commercial orchard or site were organized into three sensitivity categories based on MIC values obtained from the in vitro assay. This method allowed us to compare the MIC distributions of isolates from commercial orchards and the research plot where practical resistance to Pristine had been documented. The following categories were assigned for orchards with different sensitivity levels: (i) sensitive if the majority of isolates exhibited boscalid MICs between 0.1 and $0.5 \mu \mathrm{g} \mathrm{ml}^{-1}$, (ii) reduced sensitivity if the majority of isolates exhibited boscalid MICs between 1 and $10 \mu \mathrm{g} \mathrm{ml}^{-1}$, or (iii) resistant if at least $34 \%$ of isolates exhibited boscalid MICs $\geq 25 \mu \mathrm{g} \mathrm{ml}^{-1}$.

The seven sites with no history of fungicide applications were classified as sensitive to boscalid with MIC values that ranged from 0.1 to $0.5 \mu \mathrm{g} \mathrm{ml}^{-1}$. Approximately $97 \%$ of isolates in this sensitive group had an MIC value of $0.1 \mu \mathrm{g} \mathrm{ml}^{-1}$. Of the 31 commercial orchards sampled in 2010 and 2011 (31 unique orchards; 11 were sampled in both years), none were classified as sensitive, and 21 were classified as having a reduced sensitivity to boscalid with isolate MIC values that ranged from 0.1 to $>25 \mu \mathrm{g} \mathrm{ml}^{-1}$. Approximately $92 \%$ of isolates in this reduced sensitivity group had MIC values in the
1.0- to $10-\mu \mathrm{g} \mathrm{ml}^{-1}$ range, whereas only around $5 \%$ of isolates had MIC values $>25 \mu \mathrm{g} \mathrm{ml}^{-1}$ (Fig. 3). Lastly, 10 commercial orchards were classified as resistant to boscalid with MIC values that ranged from 0.5 to $>25 \mu \mathrm{g} \mathrm{ml}^{-1}$. Of the 11 orchards sampled in both years, 7 and 2 were classified as reduced sensitive and resistant in both years, respectively. The two other orchards from this group shifted from reduced sensitive in 2010 to resistant in 2011. Approximately $64 \%$ of isolates in this resistant group had MIC values $>25 \mu \mathrm{g} \mathrm{ml} l^{-1}$, whereas only around $12 \%$ of isolates had MIC values in the 1.0- to $10-\mu \mathrm{g} \mathrm{ml}^{-1}$ range (Fig. 3). The least sensitive orchard surveyed in this study had $\sim 96 \%$ of isolates with an MIC of $>25 \mu \mathrm{g} \mathrm{ml}^{-1}$ (Fig. 3).

Amplification of the $s d h B$ gene and molecular detection of the H260R mutation. Seven isolates were initially examined in an attempt to amplify $s d h B$ sequences using each of the three degenerate primer pairs. Primer pair SDHB-FL and SDHB-R amplified a 650-bp fragment from all seven isolates, primer pair SDHB-FS and SDHB-R amplified a 350-bp fragment from six isolates, and primer pair SDHB-FEL and SDHB-R amplified a 400-bp fragment from six isolates. A partial nucleotide sequence of the $s d h B$ gene was ultimately obtained from sequencing the amplified fragments using the appropriate degenerate primers. A search utilizing the BLASTx algorithm revealed homologies to the $s d h B$ sequences from other filamentous

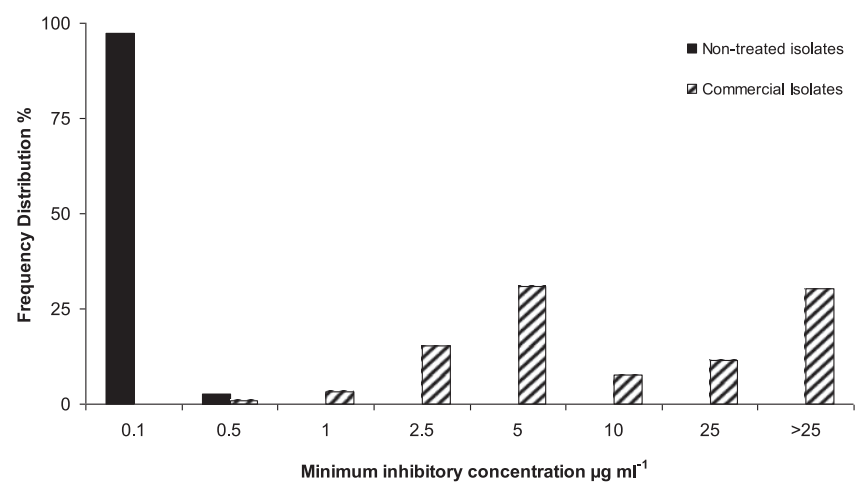

Fig. 1. Boscalid sensitivity distribution of nontreated and commercial isolates of Blumeriella jaapii sampled in 2010 and 2011. Nontreated isolates are represented by black bars, and commercial isolates are represented by hatched bars.

Table 2. Cherry leaf spot (CLS) incidence and defoliation in field trial experiments conducted at the Northwest Michigan Horticulture Research Center in Suttons Bay, Michigan

\begin{tabular}{|c|c|c|c|c|}
\hline \multirow[b]{3}{*}{ Year and treatment description ${ }^{x}$} & \multicolumn{4}{|c|}{ CLS rating $^{y}$} \\
\hline & \multicolumn{2}{|c|}{ Infection $(\%)$} & \multicolumn{2}{|c|}{ Defoliation (\%) } \\
\hline & Harvest & Postharvest & Harvest & Postharvest \\
\hline 2011 & 15 July & 25 August & 15 July & 25 August \\
\hline Boscalid + pyraclostrobin FS & $35.5 \mathrm{~b}^{\mathrm{z}}$ & $49.6 \mathrm{~b}$ & $0.9 \mathrm{~b}$ & $30.3 \mathrm{c}$ \\
\hline Fluxapyroxad + pyraclostrobin FS & $24.9 \mathrm{c}$ & $22.3 \mathrm{c}$ & $0.6 \mathrm{~b}$ & $7.5 \mathrm{~d}$ \\
\hline Trifloxystrobin FS & $27.0 \mathrm{c}$ & $69.9 \mathrm{~b}$ & $1.2 \mathrm{~b}$ & $48.8 \mathrm{~b}$ \\
\hline Untreated control & $77.8 \mathrm{a}$ & $87.1 \mathrm{a}$ & $20.7 \mathrm{a}$ & $88.4 \mathrm{a}$ \\
\hline 2012 & 29 June & 1 August & 29 June & 1 August \\
\hline Boscalid + pyraclostrobin P1 & $18.4 \mathrm{c}$ & $47.8 \mathrm{~b}$ & $6.7 \mathrm{a}$ & $30.3 \mathrm{~b}$ \\
\hline Fluxapyroxad + pyraclostrobin P1 & $16.1 \mathrm{c}$ & $22.4 \mathrm{~d}$ & $0.9 \mathrm{c}$ & $3.9 \mathrm{~d}$ \\
\hline Trifloxystrobin $\mathrm{P}$ & $25.7 \mathrm{~b}$ & $29.9 \mathrm{c}$ & $0.6 \mathrm{c}$ & $11.6 \mathrm{c}$ \\
\hline Untreated control & $65.1 \mathrm{a}$ & $90.2 \mathrm{a}$ & $3.1 \mathrm{~b}$ & $82.2 \mathrm{a}$ \\
\hline 2013 & 19 July & 22 August & 19 July & 22 August \\
\hline Boscalid + pyraclostrobin P2 & $6.1 \mathrm{~b}$ & $42.4 \mathrm{~b}$ & $0.0 \mathrm{~b}$ & $15.1 \mathrm{~b}$ \\
\hline Fluxapyroxad + pyraclostrobin P2 & $3.2 \mathrm{c}$ & $10.9 \mathrm{c}$ & $0.0 \mathrm{~b}$ & $1.9 \mathrm{c}$ \\
\hline Untreated Control & $51.1 \mathrm{a}$ & $94.4 \mathrm{a}$ & $22.0 \mathrm{a}$ & $82.9 \mathrm{a}$ \\
\hline
\end{tabular}

${ }^{x}$ Treatment description refers to compound and seasonal use. FS indicates full season. Program indicates that a combination of fungicides was used during the season for this treatment. P1 refers to program treatments run in 2012 utilizing chlorothalonil at 2,780 $\mathrm{g} \mathrm{ha}^{-1}$, and P2 refers to program treatments run in 2013 utilizing chlorothalonil at $3,363 \mathrm{~g} \mathrm{ha}^{-1}$.

${ }^{\mathrm{y}}$ Treatments were replicated four times on single-tree plots. Incidence was defined as the percentage of leaves with CLS on 20 terminal shoots per tree. Percentage defoliation was defined as $(1-$ [number of leaves/number of nodes] $) \times 100$.

${ }^{\mathrm{z}}$ Within an experiment, values followed by the same letter are not significantly different according to Fisher's least significant difference test $(P<0.05)$. 
fungi (data not shown). Generation of new primers based on the actual $B$. jaapii sequence along with successive rounds of primer walking enabled completion of the $s d h B$ sequence. Deduced amino acid sequences from the $B$. jaapii $s d h B$ sequences revealed three cysteine-rich clusters that are known to contain regions with point mutations associated with resistance to boscalid (Sierotzki and Scalliet 2013).

The $s d h B$ sequence was determined from 13 boscalid-sensitive $B$. jaapii isolates, 10 with reduced sensitivity to boscalid, and 10 boscalid-resistant isolates and aligned for comparison. Analysis of the nucleotide sequences from boscalid-sensitive and boscalidresistant isolates revealed one nucleotide difference. This analysis revealed a transversion mutation of a $\mathrm{C}$ to a $\mathrm{G}$ at nucleotide 887 of $s d h B$, resulting in a codon change from CAC to CAG. This mutation would lead to an exchange of a histidine residue to arginine at amino acid 260 (H260R), and it was observed in the $s d h B$ gene of all 10 boscalid-resistant $B$. jaapii isolates sequenced. No difference in $s d h B$ nucleotide sequence was detected between the isolates with reduced sensitivity to boscalid and the sensitive isolates (Table 3).

\section{Discussion}

Our results show that boscalid resistance in B. jaapii is widespread in Michigan tart cherry orchards. In 12 of 31 commercial orchards (29\%), the percentage of B. jaapii isolates with boscalid MICs

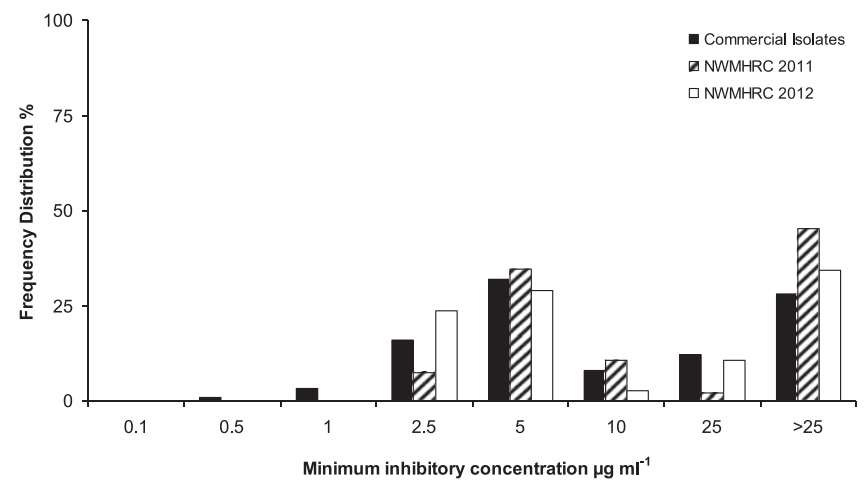

Fig. 2. Boscalid sensitivity distribution of commercial isolates of Blumeriella jaapii isolates sampled in 2010 and 2011 and research orchard isolates of B. jaapii sampled from the Northwest Michigan Horticultural Research Center (NWMHRC) in 2011 and 2012. Commercial isolates are represented by black bars, 2011 NWMHRC research orchard isolates are represented by hatched bars, and 2012 NWMHRC research orchard isolates are represented by white bars.

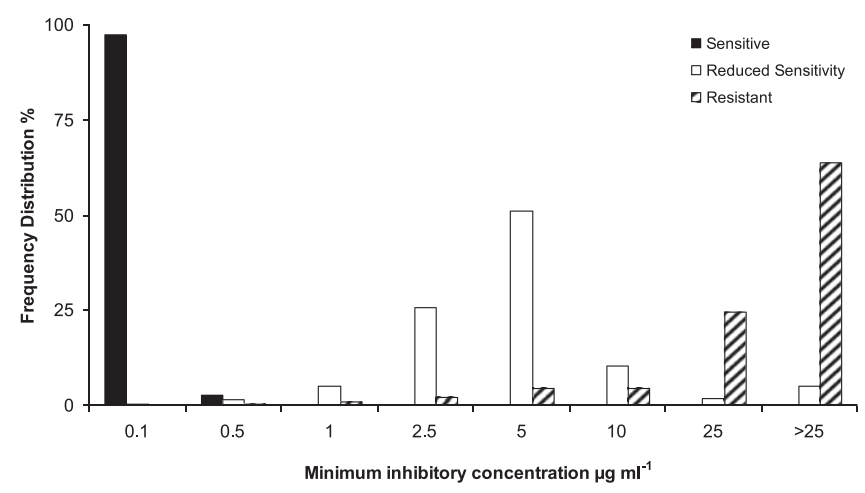

Fig. 3. Population distributions of 2010 and 2011 orchard sensitivity groups. Orchards classified as sensitive harbored a majority of Blumeriella jaapii isolates with boscalid minimum inhibitory concentrations (MICs) between 0.1 and $0.5 \mu \mathrm{g} \mathrm{ml}^{-1}$; they are identified by black bars. Orchards classified as reduced sensitive harbored a majority of $B$. jaapii populations with boscalid MICs between 1 and $10 \mu \mathrm{g} \mathrm{ml}^{-1}$; they are identified by white bars. In orchards classified as resistant, at least $34 \%$ of $B$. jaapii isolates exhibited boscalid MICs of $\geq 25 \mathrm{mg} \mathrm{ml}^{-1}$; they are identified by hatched bars. $\geq 25 \mu \mathrm{g} \mathrm{ml}^{-1}$ was similar to or higher than that observed in the population of B. jaapii from our NWMHRC fungicide test orchard, where practical resistance to boscalid was observed. We also determined that the boscalid resistance phenotype of $B$. jaapii isolates from Michigan was correlated with a point mutation in the $s d h B$ gene, resulting in a histidine to arginine amino acid exchange at position 260 in SdhB. As observed in other plant pathogenic fungi, including A. solani, B. cinerea, C. casiicola, and D. bryoniae, we observed $B$. jaapii isolates with differing levels of boscalid resistance (Avenot et al. 2012; Ishii et al. 2011; Mallik et al. 2014; Veloukas et al. 2013; Yin et al. 2011). Differences in boscalid-resistance levels are typically associated with the presence of distinct mutations in $s d h B, s d h C$, or $s d h D$. In this study, B. jaapii isolates with the reduced sensitive phenotype did not possess the point mutation that results in the H260R amino acid exchange in $s d h B$. Because all of the isolates that were never exposed to SDHI fungicides were uniformly sensitive to boscalid, we do not think that the reduced resistance phenotype occurred naturally because of variability in boscalid sensitivity within the population. Instead, we hypothesize that these isolates may harbor a different mutation(s) that we have not yet identified in any of the $s d h B, s d h C$, or $s d h D$ target genes.

In addition, we established the baseline boscalid sensitivity of nontreated $B$. jaapii populations from wild cherry hosts that had never been exposed to fungicides. These isolates were relatively sensitive, with MICs $\leq 0.5 \mu \mathrm{g} \mathrm{ml}^{-1}$. However, in orchard sites where Pristine has been utilized for CLS control, the boscalid MIC profile differed greatly. In fungicide trials conducted at the NWMHRC from 2011 to 2013, we observed a reduction in the efficacy of Pristine for CLS control to unsatisfactory levels owing to the presence of an elevated percentage of $B$. jaapii isolates with MICs of boscalid $\geq 25 \mu \mathrm{g} \mathrm{ml}^{-1}$ compared with nonexposed isolates. We surmised that the boscalid component of Pristine was responsible for the unsatisfactory control of CLS rather than the trifloxystrobin component, because we still observed effective CLS control in this block with Merivon, which contains the same trifloxystrobin component as Pristine in equivalent amounts but substitutes fluxapyroxad for boscalid. Practical resistance occurs when the frequency of resistant isolates is high enough in any given population to result in total disease control that is unsatisfactory (i.e., not commercially adequate). The orchard distribution of MICs from the $B$. jaapii NWMHRC population was highly similar to that of orchard distributions from commercial orchards in Michigan, some of which had reported losses of CLS control after applications of Pristine. Because growers had not applied four to six applications of Pristine as in our studies and did not leave unsprayed control trees, their control of CLS would be expected to be better than that observed at the NWMHRC site. However, our results indicate that resistance to boscalid in $B$. jaapii populations from commercial orchards in Michigan has reached levels of practical resistance.

Orchards classified as "reduced sensitive" had a wide range of phenotypic responses to boscalid but did not contain a high percentage of sensitive isolates. These results may indicate that $B$. jaapii isolates in orchards with reduced sensitivity have shifted but less so than in populations of orchards classified as resistant. Orchards with a reduced sensitivity profile do not contain populations with a high percentage of boscalid-resistant isolates and do not seem to be exhibiting practical resistance to Pristine. The small percentage of boscalidresistant isolates and the lack of practical resistance may be because of the different fungicide rotations used annually in these orchards. Although $B$. jaapii populations in reduced sensitivity orchards seem to be currently controlled by Pristine, the presence of boscalidresistant isolates in these orchards has the potential to quickly and dramatically change the distribution of those orchard populations after additional Pristine applications.

Resistance to boscalid of $B$. jaapii isolates has been correlated with a single-point mutation in the third cysteine-rich cluster of the $\mathrm{SdhB}$ subunit of the succinate dehydrogenase gene. The amino acid change from a histidine to an arginine was only detected in $B$. jaapii isolates that were classified as resistant in the in vitro boscalid sensitivity assay, and the amino acid position of the mutation (H260R) is conserved in other plant pathogenic fungi resistant to SDHI fungicides 
(Sierotzki and Scalliet 2013). Boscalid resistance has also been associated with point mutations in other regions of the $s d h B$ gene located within $\sim 50$-amino acid residues of $\mathrm{H} 277$ or point mutations in the $s d h C$ or $s d h D$ gene (Avenot and Michailides 2010; Avenot et al. 2012; Fernández-Ortuño et al. 2017; Hu et al. 2016; Koller 1991; Mallik et al. 2014; Popko et al. 2018; Sierotzki and Scalliet 2013; Veloukas et al. 2013; Yin et al. 2011).

With the recent registration of several newer SDHI fungicides for plant disease management (including fluopyram and fluxapyroxad for CLS), we need to better understand if existing mutations in $s d h$ genes can confer cross-resistance among these compounds and if newer mutations targeting other SDHI fungicides confer crossresistance to boscalid. For example, examinations of boscalidresistant field isolates of $C$. casiicola and D. bryoniae have shown that these isolates were sensitive to fluopyram (Avenot et al. 2012; Ishii et al. 2011). These fungi harbored amino acid exchanges at the conserved histidine residue (H278Y in $C$. casiicola and either H272R or H272Y in D. bryoniae). Similarly, boscalid-resistant $A$. solani isolates harboring $\mathrm{H} 278 \mathrm{R}$ or $\mathrm{H} 278 \mathrm{Y}$ in $\mathrm{SdhB}$ or other single exchanges in SdhC and SdhD were sensitive to fluopyram (Mallik et al. 2014); however, another study identified three $A$. solani isolates with cross-resistance to boscalid and fluopyram (Miles et al. 2014). Further complicating matters, some isolates of $B$. cinerea that were resistant to boscalid and fluopyram harbored the H272Y mutation in $s d h B$, although analyses for mutations in $s d h C$ or $s d h D$ were not conducted in these studies (Fernández-Ortuño et al. 2017; Hu et al. 2016).

Table 3. Codon and amino acid residues at position 260 of the succinate dehydrogenase subunit $\mathrm{b}$ gene of 33 Blumeriella jaapii isolates grouped by boscalid sensitivity groups ${ }^{\mathrm{z}}$

\begin{tabular}{|c|c|c|c|}
\hline Isolate & $\begin{array}{c}\text { Boscalid } \\
\text { phenotype }\end{array}$ & $\begin{array}{c}\text { Codon in } S D H B \\
\text { sequence }\end{array}$ & $\begin{array}{l}\text { Amino acid } \\
\text { residue }\end{array}$ \\
\hline 11PEBJ-1 & $S$ & CAC & $\mathrm{H}$ (histidine) \\
\hline 11PEBJ-3 & $\mathrm{S}$ & CAC & $\mathrm{H}$ \\
\hline 11PEBJ-4 & S & CAC & $\mathrm{H}$ \\
\hline 11PEBJ-9 & $S$ & CAC & $\mathrm{H}$ \\
\hline 11PEBJ-11 & S & CAC & $\mathrm{H}$ \\
\hline 11LIBJMR-1 & S & CAC & $\mathrm{H}$ \\
\hline 11LIBJMR-3 & $S$ & CAC & $\mathrm{H}$ \\
\hline 11LIBJMR-4 & S & CAC & $\mathrm{H}$ \\
\hline 11LIBJMR-5 & S & CAC & $\mathrm{H}$ \\
\hline 11LIBJMR-6 & S & CAC & $\mathrm{H}$ \\
\hline 11LIBJMR-7 & S & CAC & $\mathrm{H}$ \\
\hline 11LIBJMR-8 & S & CAC & $\mathrm{H}$ \\
\hline 11LIBJMR-9 & $S$ & CAC & $\mathrm{H}$ \\
\hline 10BLGO-2 & $\mathrm{RS}$ & CAC & $\mathrm{H}$ \\
\hline 10BOGW-1 & $\mathrm{RS}$ & CAC & $\mathrm{H}$ \\
\hline 10BOGW-24 & $\mathrm{RS}$ & CAC & $\mathrm{H}$ \\
\hline 10BWPB-24 & $\mathrm{RS}$ & CAC & $\mathrm{H}$ \\
\hline 10BWPB-29 & $\mathrm{RS}$ & CAC & $\mathrm{H}$ \\
\hline 10BOW-1 & $\mathrm{RS}$ & CAC & $\mathrm{H}$ \\
\hline 10BOW-3 & RS & CAC & $\mathrm{H}$ \\
\hline 10BOW-4 & $\mathrm{RS}$ & CAC & $\mathrm{H}$ \\
\hline 10BOW-9 & $\mathrm{RS}$ & CAC & $\mathrm{H}$ \\
\hline 10BOW-12 & RS & CAC & $\mathrm{H}$ \\
\hline 10BWPB-21 & $\mathrm{R}$ & CGC & $\mathrm{R}$ (arginine) \\
\hline 10BWPB-22 & $\mathrm{R}$ & CGC & $\mathrm{R}$ \\
\hline 10BWPB-25 & $\mathrm{R}$ & CGC & $\mathrm{R}$ \\
\hline 10BWPB-27 & $\mathrm{R}$ & CGC & $\mathrm{R}$ \\
\hline 10BWPB-30 & $\mathrm{R}$ & $\mathrm{CGC}$ & $\mathrm{R}$ \\
\hline 10BOW-5 & $\mathrm{R}$ & CGC & $\mathrm{R}$ \\
\hline 10BOW-14 & $\mathrm{R}$ & CGC & $\mathrm{R}$ \\
\hline 10BOW-15 & $\mathrm{R}$ & CGC & $\mathrm{R}$ \\
\hline 10BOW-16 & $\mathrm{R}$ & CGC & $\mathrm{R}$ \\
\hline 10BOW-17 & $\mathrm{R}$ & CGC & $\mathrm{R}$ \\
\hline
\end{tabular}

${ }^{\mathrm{z}}$ Amino acid residues were changed from a histidine to arginine for all resistant isolates sequenced. Boscalid sensitivity groups are as follows: R, resistant; RS, reduced sensitive; S, sensitive.
A mutation within $s d h B$ resulting in a different amino acid exchange $(\mathrm{P} 225 \mathrm{~F})$ has been associated with cross-resistance to boscalid, fluopyram, fluxapyroxad, and bixafen and was detected from one field isolate of $B$. cinerea from Greece (Veloukas et al. 2013). B. cinerea isolates from the eastern United States and Spain with resistance to boscalid, fluopyram, fluxapyroxad, and penthiopyrad harbored the P225F mutation or an N230I mutation within $s d h B$ (Fernández-Ortuño et al. 2017; Hu et al. 2016). A large-scale temporal and geographical sampling study has also shown that the frequencies of occurrence of various SDHI resistance-conferring mutations can change dramatically among field populations of $A$. solani (Bauske et al. 2018). Our study will provide a collection of B. jaapii isolates with varying levels of boscalid sensitivity and at least one known $s d h B$ mutation for the evaluation of cross-resistance to additional SDHIs relevant to CLS management, including fluopyram and fluxapyroxad.

The effective management of CLS in commercial tart cherry orchards in Michigan typically requires up to four applications of site-specific fungicides per year. This number of fungicide applications is owing to the high susceptibility of the predominant tart cherry Montmorency to CLS, and it also reflects restrictions on labels of registered multisite fungicides that affect either the length of the preharvest interval or the maximum allowable rate per application. The number of effective fungicides available to growers for the control of CLS has decreased over the years as the sterol demethylation inhibitor group was lost to resistance (Proffer et al. 2006), and our results indicate the loss of boscalid to resistance. This limitation on the number of available modes of action greatly increases the risk of fungicide resistance through increases in the number of applications of individual site-specific fungicides each season. The possible occurrence of cross-resistance among SDHIs and/or the evolution of resistance to the newer SDHIs fluopyram and fluxapyroxad are additional concerns. Both the reliance of the tart cherry industry on the CLSsusceptible Montmorency and fungicide resistance evolution in $B$. jaapii reduce the prospects for the long-term sustainable production of tart cherries.

\section{Acknowledgments}

We thank Gail Ehret, Gayle McGhee, Bill Klein, Myron Anderson, and Karen Powers for assistance in conducting field trials and analyzing field data.

\section{Literature Cited}

Ackrell, B. A. C. 2000. Progress in understanding structure-function relationships in respiratory chain complex II. FEBS Lett. 466:1-5.

Avenot, H. F., and Michailides, T. J. 2007. Resistance to boscalid fungicide in Alternaria alternata isolates from pistachio in California. Plant Dis. 91: 1345-1350.

Avenot, H. F., and Michailides, T. J. 2010. Progress in understanding molecular mechanisms and evolution of resistance to succinate dehydrogenase inhibiting (SDHI) fungicides in phytopathogenic fungi. Crop Prot. 29:643-651.

Avenot, H. F., Sellam, A., Karaoglanidis, G., and Michailides, T. J. 2008 Characterization of mutations in the iron-sulphur subunit of succinate dehydrogenase correlating with boscalid resistance in Alternaria alternata from California pistachio. Phytopathology 98:736-742.

Avenot, H. F., Sellam, A., and Michailides, T. J. 2009. Characterization of mutations in the membrane-anchored subunits AaSDHC and AaSDHD of succinate dehydrogenase from Alternaria alternata isolates conferring field resistance to the fungicide boscalid. Plant Pathol. 58:1134-1143.

Avenot, H. F., Thomas, A., Gitaitis, R. D., Langston, D. B., and Stevenson, K. L. 2012. Molecular characterization of boscalid- and penthiopyrad-resistant isolates of Didymella bryoniae and assessment of their sensitivity to fluopyram. Pest Manag. Sci. 68:645-651.

Bauske, M. J., Mallik, I., Yellareddygari, S. K. R., and Gudmestad, N. C. 2018. Spatial and temporal distribution of mutations conferring QoI and SDHI resistance in Alternaria solani across the United States. Plant Dis. 102:349-358.

Cecchini, G. 2003. Function and structure of complex II of the respiratory chain. Annu. Rev. Biochem. 72:77-109.

Chen, F., Liu, X., Chen, S., Schnabel, E., and Schnabel, G. 2013. Characterization of Monilinia fructicola strains resistant to both propiconazole and boscalid. Plant Dis. 97:645-651.

Eisensmith, S. P., and Jones, A. L. 1981. A model for detecting infection periods of Coccomyces hiemalis on sour cherry. Phytopathology 71:728-732.

Fernández-Ortuño, D., Pérez-García, A., Chamorro, A., de la Peña, E., de Vicente, A., and Torés, J. A. 2017. Resistance to the SDHI fungicides boscalid, 
fluopyram, fluxapyroxad, and penthiopyrad in Botrytis cinerea from commercial strawberry fields in Spain. Plant Dis. 101:1306-1313.

Georgopoulos, S. G., Chrysayi, M., and White, G. A. 1975. Carboxin resistance in haploid, the heterozygous diploid, and the plant-parasitic dicaryotic phase of Ustilago maydis. Pestic. Biochem. Physiol. 5:543-551.

Howell, G. S., and Stackhouse, S. S. 1973. The effect of defoliation time on acclimation and dehardening in tart cherry (Prunus cerasus L.). J. Am. Soc. Hortic. Sci. 98:132-136.

Hu, M.-J., Fernández-Ortuño, D., and Schnabel, G. 2016. Monitoring resistance to SDHI fungicides in Botrytis cinerea from strawberry fields. Plant Dis. 100: 959-965.

Ishii, H., Miyamoto, T., Ushio, S., and Kakishima, M. 2011. Lack of cross resistance to a novel succinate dehydrogenase inhibitor, fluopyram, in highly boscalid-resistant isolates of Corynespora cassiicola and Podosphaera xanthii. Pest Manag. Sci. 67:474-482.

Keinath, A. P. 2012. Differential sensitivity to boscalid in conidia and ascospores of Didymella bryoniae and frequency of boscalid-insensitive isolates in South Carolina. Plant Dis. 96:228-234.

Keitt, G. W., Blodgett, E. C., Wilson, E. E., and Magie, R. O. 1937. The epidemiology and control of cherry leaf spot. In: University of Wisconsin Agricultural Experiment Station Research Bulletin 132.

Koller, W. 1991. Fungicide resistance in plant pathogens. Pages 679-720 in: CRC Handbook of Pest Management in Agriculture, 2nd Ed., D. Pimentel, ed. Vol. 2. CRC Press, Boca Raton, FL.

Leroux, P., Gredt, M., Leroch, M., and Walker, A. S. 2010. Exploring mechanisms of resistance to respiratory inhibitors in field strains of Botrytis cinerea, the causal agent of gray mold. Appl. Environ. Microbiol. 76:6615-6630.

Ma, Z., Proffer, T. J., Jacobs, J. L., and Sundin, G. W. 2006. Overexpression of the $14 \alpha$-demethylase target gene (CYP51) mediates fungicide resistance in Blumeriella jaapii. Appl. Environ. Microbiol. 72:2581-2585.

Mallik, I., Arabiat, S., Pasche, J. S., Bolton, M. D., Patel, J. S., and Gudmestad, N. C. 2014. Molecular characterization and detection of mutations associated with resistance to succinate dehydrogenase-inhibiting fungicides in Alternaria solani. Phytopathology 104:40-49.

Miles, T. D., Miles, L. A., Fairchild, K. L., and Sharton, P. S. 2014. Screening and characterization of resistance to succinate dehydrogenase inhibitors in Alternaria solani. Plant Pathol. 63:155-164.

Miyamoto, T., Ishii, H., Stammler, G., Koch, A., Ogawara, T., Tomita, Y., Fountaine, J. M., Ushio, S., Seko, T., and Kobori, S. 2010. Distribution and molecular characterization of Corynespora cassiicola isolates resistant to boscalid. Plant Pathol. 59:873-881.

Popko, J. T., Sang, H., Lee, J., Yamada, T., Hoshino, Y., and Jung, G. 2018. Resistance of Sclerotinia homoeocarpa field isolates to succinate dehydrogenase inhibitor fungicides. Plant Dis. 102:2625-2631.

Proffer, T. J., Berardi, R., Ma, Z., Nugent, J. E., Ehret, G. R., McManus, P. S. Jones, A. L., and Sundin, G. W. 2006. Occurrence, distribution, and polymerase chain reaction-based detection of resistance to sterol demethylation inhibitor fungicides in populations of Blumeriella jaapii in Michigan. Phytopathology 96:709-717.

Proffer, T. J., Lizotte, E., Rothwell, N. L., and Sundin, G. W. 2013 Evaluation of dodine, fluopyram and penthiopyrad for the management of leaf spot and powdery mildew of tart cherry, and fungicide sensitivity screening of Michigan populations of Blumeriella jaapii. Pest Manag. Sci. 69:747-754.

Sierotzki, H., and Scalliet, G. 2013. A review of current knowledge of resistance aspects for the next-generation succinate dehydrogenase inhibitor fungicides. Phytopathology 103:880-887.

Stammler, G., and Speakman, J. 2006. Microtiter method to test the sensitivity of Botrytis cinerea to boscalid. J. Phytopathol. 154:508-510.

Sundin, G. W., Ehret, G. R., Proffer, T. J., Nugent, J. E., Klein, W. M., Anderson, M. D., and Rothwell, N. L. 2006. Evaluation of new fungicides rotations for resistance management on Montmorency tart cherries in NW Michigan, 2005. Fungic. Nematic. Tests 61:STF004.

Veloukas, T., Leroch, M., Hahn, M., and Karaoglanidis, G. S. 2011. Detection and molecular characterization of boscalid-resistant Botrytis cinerea isolates from strawberry. Plant Dis. 95:1302-1307.

Veloukas, T., Markoglou, A. N., and Karaoglandis, G. S. 2013. Differential effect of SdhB gene mutations on the sensitivity to SDHI fungicides in Botrytis cinerea. Plant Dis. 97:118-122.

Wharton, P., Fairchild, K., Belcher, A., and Wood, E. 2012. First report of in-vitro boscalid-resistant isolates of Alternaria solani causing early blight of potato in Idaho. Plant Dis. 96:454.

Yin, Y. N., Kim, Y. K., and Xiao, C. L. 2011. Molecular characterization of boscalid resistance in field isolates of Botrytis cinerea from apple. Phytopathology 101:986-995.

Zhang, C. Q., Yuan, S. K., Sun, H. Y., Qi, Z. Q., Zhou, M. G., and Zhu, G. N. 2007. Sensitivity of Botrytis cinerea from vegetable greenhouses to boscalid. Plant Pathol. 56:646-653. 